\title{
Mitral Valve Annulus
}

National Cancer Institute

\section{Source}

National Cancer Institute. Mitral Valve Annulus. NCI Thesaurus. Code C127306.

A saddle-shaped, fibrous structure that provides support to the mitral valve leaflets, and functions to contract during ventricular systole, thereby providing complete closure of the mitral valve and preventing regurgitant blood flow into the left atrium. 